\title{
Qual política ao psicanalista (e seu corpo) na universidade?
}

\author{
Carolina Escobar de Almeida Prado
}

\begin{abstract}
Resumo
Este texto tem por objetivo ocupar-se do debate sobre a inserção da psicanálise na universidade e, mais especificamente, de uma das formas dessa inserção: os cursos de graduação. Para isso, buscaram-se textos de Sigmund Freud visando a possíveis diretrizes para sua sustentação e transmissão da psicanálise nesses espaços. Ainda que se sustente como campo de saber, o exercício da psicanálise requer uma formação especial, e, somado a isso, a universidade, como o lugar de produção de ciência e de verdade(s), pode levar-nos ao pior. Então, o que leva um psicanalista à escolha de ser professor de psicanálise em um curso de graduação? Qual política ao psicanalista (e seu corpo) na universidade?
\end{abstract}

\section{Palavras-chave:}

Psicanálise; Universidade; Graduação.

\section{What is the policy for the psychoanalyst (and his body) at the university?}

\begin{abstract}
This text aims to deal with the debate on the insertion of psychoanalysis in the University and, more specifically, one of the forms of this insertion: the undergraduate courses. For this, we sought texts by Sigmund Freud searching for possible guidelines for its support and transmission of the psychoanalysis in these spaces. Although sustained as a field of knowledge, the exercise of psychoanalysis requires special training and, in addition, the University, as the place of production of science and truth(s), can lead us to the worst. So, what makes a psychoanalyst choose to be a psychoanalysis teacher in an undergraduate course? What is the policy for the psychoanalyst (and his body) at the university?
\end{abstract}

\section{Keywords:}

Psychoanalysis; University; Undergraduate course. 


\title{
¿Qué política para el psicoanalista (y su cuerpo) en la universidad?
}

\begin{abstract}
Resumen
Este texto tiene como objetivo abordar el debate sobre la inserción del psicoanálisis en la Universidad y, más específicamente, una de las formas de esta inserción: los cursos de grado. Para esto, buscamos textos de Sigmund Freud que indicaron posibles principios para sostener y permitir la transmisión del psicoanálisis en esos espacios. Aunque sostenido como un campo de conocimiento, el ejercicio del psicoanálisis requiere capacitación especial y, además de eso, la Universidad como lugar de producción de ciencia y verdad(es), puede llevarnos a lo peor. Entonces, ¿qué lleva a que un psicoanalista elija ser profesor de psicoanálisis en una carrera de grado? ¿Qué política para el psicoanalista (y su cuerpo) en la universidad?
\end{abstract}

\section{Palabras clave:}

Psicoanálisis; Universidad; Grado.

\section{Quelle politique pour le psychanalyste (et son corps) à l'université?}

\begin{abstract}
Résumé
Ce texte a pour but d'aborder le débat sur l'insertion de la psychanalyse à l'université, et notamment, sur l'une des formes de cette insertion : les cours de licence. Nous avons à cet effet cherché des textes de Sigmund Freud, visant à en dégager des lignes directrices possibles pour le soutien et la transmission de la psychanalyse dans ces espaces. Bien qu'il se soutienne en tant que domaine de savoir, l'exercice de la psychanalyse exige une formation spéciale ; en outre, l'université, en tant que le lieu de production de science et de vérité(s), peut nous conduire au pire. Alors qu'est-ce qui fait un psychanalyste choisir d'être professeur de psychanalyse dans un cours de licence? Quelle politique le psychanalyste (et son corps) a-t-il à l'université ?
\end{abstract}

\section{Mots-clés :}

Psychanalyse ; Université ; Licence. 
A origem deste texto está em interrogações sobre a transmissão da psicanálise na universidade. Esse não é um tema inaugural, posto que não é de hoje que a psicanálise está inserida no contexto universitário; porém, aqui, ocupo-me de uma das formas dessa inserção, visando a diretrizes para sua sustentação: a psicanálise em cursos de graduação.

“Deve-se ensinar a psicanálise nas universidades?", pergunta-se Freud (1919/2010) em um de seus textos. Por que não se deveria? A própria indagação freudiana indica que a aproximação da psicanálise com a universidade nunca se deu sem hesitações, mas por qual razão elas aparecem?

Uma das formas de compreender a hesitação freudiana parte de seu esforço em definir que a psicanálise poderia sustentar-se como um campo, e não como uma especialização ou modalidade de intervenção vinculada a outro campo de saber. Encontramos a construção dessa argumentação tanto no texto citado quanto em outros momentos de sua obra, como em "A questão da análise leiga: diálogo com um interlocutor imparcial" (Freud, 1926/2014a) e "O futuro de uma ilusão" (Freud, 1927/2014b).

Em “A questão da análise leiga" (1926/2014a, p. 189), Freud é incisivo ao dizer que "Os médicos não têm o direito histórico à posse exclusiva da psicanálise (...)”, diante da proposta de que somente eles poderiam ser psicanalistas. Sua preocupação é de a psicanálise tornar-se uma especialidade médica. Já em "O futuro de uma ilusão" (Freud, 1927/2014b), ele distancia o tratamento psicológico da religião com receio de que ela fosse usada por seus representantes em práticas religiosas; afirma que, para ele, “(...) esclarecer os enigmas do universo e nos reconciliar com os sofrimentos da vida (...) é um notável problema psicológico" (Freud, 1927/2014b, p. 262), e ocupa-se da tese de que o religioso teria a função psíquica da evitação do desamparo estrutural.

Toda a argumentação freudiana está norteada pela delimitação do campo psicanalítico como próprio; ou seja, como nova disciplina científica, já que a psicanálise "(...) define seu campo, seus métodos, sua problemática própria” (Mezan, 2002, p. 437).

O impasse entre psicanálise e universidade apresenta-se no fato de que, ainda que se sustente como campo de saber, o exercício da psicanálise requer uma formação especial e, por isso, "faculdades de psicanálise não existem" (Freud, 1927/2014b, p. 220). Diante disso, Freud localiza três modalidades de transmissão da psicanálise - a teórica, a pesquisa e a formação clínica - e esclarece que, no cenário acadêmico,

(...) este ensino [psicanálise] somente poderia ser ministrado de forma dogmática, em aulas teóricas, pois quase não haveria oportunidade para 
experimentos ou demonstrações práticas. Para a pesquisa que o professor de psicanálise deverá realizar, bastaria ele ter acesso ao ambulatório com pacientes "neuróticos" (...).

Por fim, cabe considerar a objeção de que dessa forma o estudante (...) jamais aprenderá realmente a psicanálise. Isso é verdadeiro se pensarmos no efetivo exercício da psicanálise, mas para os propósitos em vista é suficiente que ele aprenda algo sobre e com a psicanálise. (Freud, 1919/2010, pp. 380-381)

Com esse trecho, deparamo-nos com o fato de que a transmissão nem sempre se dá da mesma forma em psicanálise; assim como que cada uma dessas formas diferentes de transmissão norteia-se por um objetivo específico.

Parece que a proposta freudiana vislumbra a inserção da psicanálise na universidade de duas formas: em disciplinas teóricas nos cursos de graduação, momento em que há o primeiro contato com esse campo e em que se "aprenda algo sobre e com a psicanálise"; e pela via da pesquisa - não à toa há psicanálise também na pós-graduação. Nessa forma, visa-se a uma articulação teórico-clínica que parte da experiência clínica do pesquisador, somada ao método psicanalítico de investigação - aquele que conta com a presença dos pilares técnicos (associação livre, atenção flutuante e manejo da transferência e das resistências) na busca dos dados de pesquisa.

O interessante é que em nenhuma dessas modalidades Freud concebe que o resultado será a formação de um psicanalista; em suas palavras (Freud, 1926/2014a, p. 195), “(...) enfatizo a exigência de que não deve exercer a psicanálise quem não tenha adquirido o direito de fazê-lo, mediante uma formação específica”. Isso significaria dizer que o psicanalista

(...) pode prescindir da universidade, sem prejuízos para sua formação. Pois o que ele necessita teoricamente pode ser obtido na literatura especializada e aprofundado nas reuniões científicas das sociedades psicanalíticas, assim como na troca de ideias com os membros mais experientes. Quanto à experiência prática, além do que aprende na análise pessoal ele a adquire ao tratar pacientes sob o aconselhamento e supervisão de colegas já reconhecidos. (Freud, 1919/2010, p. 378)

E aí está o famoso tripé de formação em psicanálise, e é com e a partir dele que nos tornamos psicanalistas.

Mas, então, o que leva um psicanalista à escolha de ser professor de psicanálise em um curso de graduação? Qualquer resposta que universalize essa motivação é perigosa, sabemos. O que posso fazer é contar-lhes como essa decisão se deu para 
mim: alguns anos depois de ter me formado psicóloga, acabei encontrando um de meus professores em uma situação informal. Pouco depois do início da conversa, ele me perguntou: “Mas, Carol, o que é o Inconsciente, afinal?". Nossa! Foi um impacto, confesso!

A essa altura, em minha formação, já atendia, frequentava o Fórum do Campo Lacaniano, fazia minha análise pessoal e também supervisão; mas, ali, senti-me convocada em minhas entranhas. O que houve ali foi uma queda da própria imagem que tinha dos professores universitários como detentores de muito saber. Nunca havia concebido que um professor (ainda que não fosse de psicanálise) não pudesse saber sobre o Inconsciente - era só ler Freud, não? Ele não precisava saber disso para ser professor?

Retroativamente, também me dei conta de que, se não tivesse encontrado Freud em minha graduação, talvez não estivesse aqui hoje. Percebi também que era grande a quantidade de analistas e colegas queridos que haviam escolhido a formação em psicanálise após o contato com a psicanálise em seus cursos universitários.

A soma dessas duas cenas trouxe muitas perguntas; mas duas delas me acompanham até hoje: "Qual o futuro da psicanálise, se os psicanalistas tirarem o corpo fora das universidades e não se ocuparem dos cursos de graduação?" e "Como transmitir sem en(corpo)rar o lugar de quem sabe das coisas?".

Definitivamente, a primeira pergunta é o que sustenta o lugar de psicanalista-professora em mim, e ela insiste! Sinto-a comigo todas as vezes que entro em sala de aula. Já a segunda é de outra ordem; ela conta do cuidado com a institucionalização das relações de poder e de como se pode fazer o saber circular para além do que se pode acessar com a racionalidade do pensamento - como Lacan tanto nos alerta.

Como fazer passar também pelo corpo, pelo desejo, pela divisão do sujeito?

$\mathrm{Na}$ universidade, sinto o tempo todo que é preciso cuidado! Como lugar conhecido por ser onde se produz e reside a ciência, e portanto, verdade(s), a universidade pode levar-nos ao pior: ao adoecimento do corpo, ao silenciamento das perguntas, à inibição do pensamento e à angústia.

Para além disso, também é um lugar em que há impasses por todos os lados. $\mathrm{Na}$ busca da transmissão da psicanálise, um psicanalista-professor topa com a burocracia pedagógica e institucional (provas, planos de ensino, controle de faltas, relatórios etc.) que, muitas vezes, está no avesso de uma ética que se guie pelo desejo. Há também - e o tempo todo - a tensão entre os campos da psicologia e da psicanálise, e é preciso sustentá-la; mas talvez o perigo em, em vez de promover tensão, promover polarização e rivalidade. Há campo "melhor” que outro?

Essa pergunta leva-nos a um terceiro ponto: o contato com diferentes abordagens psicológicas e teorias sobre o Humano - essa tem sido uma experiência de 
bastante potência. A razão disso está no esforço de não operar por uma lógica dogmática feita com dialetos próprios e de difícil aproximação; isso joga a psicanálise para fora dos debates científicos, da possível construção de diálogo com outros campos, e reforça a imagem do psicanalista como alguém que "fala difícil".

Esse posicionamento pode levar ao estabelecimento de relações de poder sustentadas no lugar de quem sabe mais. Mais que os alunos, mais que os colegas de trabalho. Qual seria o critério para isso? Estar em meio a outras disciplinas científicas é deparar-se com o fato de que a psicanálise é uma verdade. O interessante disso é que esse posicionamento parece ser coerente com uma das novidades que a própria psicanálise - mais especificamente a lacaniana - oferece para o campo da ciência: a lógica do não-todo.

Sobre isso, Vorcaro (2013, p. 41) afirma que “(..) a existência da psicanálise na universidade (...) obriga a interlocução da psicanálise com as disciplinas com quem partilha territórios vizinhos e com as que lhe fazem litoral, franqueando a possibilidade de responder por sua práxis".

Então, aí a universidade pode ser um lugar de circulação do saber.

Ah! O saber! É de impressionar a novidade presente no posicionamento de Freud diante dele. Quando propõe a associação livre como "regra fundamental da psicanálise", rompe com a relação de poder presente na figura daquele que sabe das coisas (e das pessoas), para propor que o que está em jogo é a oferta das condições necessárias para se desejar saber. Não seria esta a função de um psicanalista que se torna professor universitário: promover um giro na relação com o saber?

Não se sai psicanalista da universidade, mas será que não é possível sair interrogado por ela? E, quem sabe, se assim o desejar, buscar sua formação como psicanalista? Bom, aí, estamos de volta ao tripé!

As diretrizes apresentadas por Freud mostram-nos que, na graduação, o objetivo da inserção da psicanálise está em que se possa aprender "algo sobre e com a psicanálise". Talvez aprender algo sobre a psicanálise diria respeito a todo arcabouço teórico-conceitual disponível nos textos psicanalíticos; assim, conhecer a importância histórica do discurso psicanalítico ao apresentar um novo paradigma sobre o Humano. Enquanto aprender algo com a psicanálise poderia ser extrair algo sobre sua ética, já que se norteia pelo desejo e aponta para uma nova possibilidade diante das relações de poder e da alienação ao Outro.

Mas, então, qual política ao psicanalista (e seu corpo) na universidade? Após o caminho percorrido até aqui, é possível levantar dois pontos que podem auxiliar na sustentação da psicanálise na ambiente universitário. Primeiro, que a política do psicanalista-professor norteia-se pelo fato de que “(...) haveria conexão entre psicanálise e universidade, a depender menos do conteúdo do que dos atos com os quais o professor fazia e mostrava seu saber" (Vorcaro, 2013, p. 39). Sua política aparece em seu posicionamento, que, quando ético, transmite. 
O que nos leva a pensar em seu corpo. Como depositário de transferência, há perigos narcísicos - e mais uma vez éticos - que um psicanalista-professor deve enfrentar. Um psicanalista empresta seu corpo para o estabelecimento da transferência ao dirigir uma análise; seria diferente com um psicanalista-professor?

A transferência tem como eixo a noção de sujeito suposto saber. (...) Entretanto, o psicanalista só se habilita à função ao diferenciar sua pessoa desse lugar que lhe é atribuído, pois[,] caso ele adira a esse equívoco, supondo-se encarnar o saber, ele exercerá poder de sugestão e de coação, mas dissolverá a possibilidade de aí haver uma psicanálise. (Vorcaro, 2013, p. 47)

Diante disso, a possibilidade em sustentar a psicanálise na universidade parece estar no psicanalista-professor fazer de seu corpo um representante do discurso psicanalítico e carregar, em seus atos, a marca de uma ética.

\section{Referências bibliográficas}

Freud, S. (2010). Deve-se ensinar a psicanálise nas universidades?. In S. Freud. Obras completas (Paulo César de Souza, Trad. e Ed.) (1a ed., Vol. 14, pp. 377-381). São Paulo: Companhia das Letras. (Trabalho original publicado em 1919)

Freud, S. (2014a). A questão da análise leiga: diálogo com um interlocutor imparcial. In S. Freud. Obras completas (Paulo César de Souza, Trad. e Ed.) (1a ed., Vol. 17, pp. 124-230). São Paulo: Companhia das Letras. (Trabalho original publicado em 1926)

Freud, S. (2014b). O futuro de uma ilusão. In S. Freud. Obras completas (Paulo César de Souza, Trad. e Ed.) (1a ed., Vol. 17, pp. 231-301). São Paulo: Companhia das Letras. (Trabalho original publicado em 1927)

Mezan, R. (2002). Sobre a epistemologia da psicanálise. In R. Mezan. Interfaces da psicanálise (pp. 436-519). São Paulo: Companhia das Letras.

Vorcaro, A. (2013). Psicanálise e universidade: "qual transmissão"? In A. Vorcaro. Psicanálise e mal-estar na universidade (pp. 37-53). Campinas: Mercado de Letras.

Recebido: 20/10/2019

Aprovado: 26/02/2020 
